\title{
O olhar do adolescente sobre saúde: um estudo de representações sociais
}

\author{
The look of teenagers about health: a study on social representation
}

Luiza M aria Figueira Cromack ${ }^{1}$

Ivani Bursztyn ${ }^{2}$

Luiz Fernando Rangel Tura ${ }^{2}$

${ }^{1}$ Secretaria M unicipal de Saúde do Rio de Janeiro, Programa de Promoção da Saúde. Rua Professor Gabizo, 174/507.

20 271-062 Rio de Janeiro RJ.cromack@ig.com.br

${ }^{2}$ Faculdadede M edicina, UniversidadeFederal do Rio deJaneiro.
Abstract Studying the social representations elaborated by adolescents aims to define a purpose to evaluate the Adolescent $\mathrm{H}$ ealthcare Program (PROSAD) in the city of Rio de Janeiro. The study is based on the Social Representation Theory using its structural approach. A word evocation test and a questionnaire with closed and open questions have been used. Participants were 1843 pupils, 12 to 18 year old from the 10 programmatic areas of the city. A comparison have been made between $12 / 13$ and 17/18 year-old group. The study found as common components at the central core important, feeding, doctors and hospital. Common components of the peripheral system were only body and sex. By associating the representation and practices in health it is not intended to reinforce the belief about a direct relationship between social representations and practices, but to stress the regulatory function of the representation, a practical knowledge which provides a frame for opinions, attitudes and behaviors. To the PROSAD remains the challenge of demonstrating to professionals these RSS, in order to improve participation and partnership that allow to check different points of view, making service suitable to user. As well to provide forums to support adolescent to discuss their role as citizens in evaluating and reorienting the service offered.

Key words Adolescent, Health, Social representation
Resumo 0 estudo das representações sociais desaúde (RSS) elaboradas por adolescentes objetiva conceber caminhos para avaliar a implantação do Programa de Saúde do Adolescente (PROSAD) no Rio de Janeiro. Baseou-se na teoria das representações sociais na sua abordagem estrutural. Foram utilizados teste de evocação de palavras e questionário com questões fechadas eabertas. Participaram 1.843 adolescentes de 12 a 18 anos distribuídos nas dez áreas programáticas municipais. Compararam-se as estruturas das RSS dos sujeitos com 12/13 e17/18 anos. São componentes comuns do núcleo central das RSS nesses estratos: importante, alimentação, médicos e hospital; no sistema periférico: corpo e sexo. Ao se associar representações e práticas em saúde, não se quer estabelecer a crença de uma relação linear entre representações sociais e práticas, mas consi derar a função reguladora das representações, um saber prático que se estrutura como um guia de opiniões, atitudes e comportamentos. Ao PROSAD cabe o desafio de fazer seus profissionais conhecerem estas RSS, valorizando mais os jovens nos serviços para discutir divergências, incorporar diferenças, explorar mais o seu potencial, criando fóruns que possi bilitem aos adolescentes a di scussão de seu papel como cidadãos na avaliação er eformulação dos serviços oferecidos.

Palavras-chave Adolescentes, Saúde, Representações sociais 
Introdução

O campo de estudo da adolescência em geral e, especificamente, da atenção à saúde do adolescente tem sido cada vez mais explorado, seja pelo aumento significativo desta população, seja por questões quea envolvem etornam-se social mentemuito perturbadoras, tais como a gravidez, as doenças sexualmente transmissíveis (DST), incluindo a aids, ou ainda questões ligadas ao uso de drogas e violência. Contudo, estudos nestas áreas são relativamente novos, o que faz com esses temas sejam de discussão recente e, talvez por isso, polêmicos ou motivo de conflitos externos e internos ${ }^{1,2,3}$. No campo das representações sociais, observa-se um interesse cada vez maior pela área da saúde. $M$ ais recentemente este interesse pela saúde agrega estudos com adolescente e, da mesma forma que ocorreem outros campos, frequentemente essetem sido abordando como sujeito deriscos relacionados à sexualidadeeàs DST, especialmente, aids, gravidez e violência. N este contexto, houve, inclusive, a exploração do conceito de vulnerabilidade ligado a suas práticas e atitudes ${ }^{1,4}$.

0 presente estudo teve como objeto as representações sociais de saúde construídas por adolescentes matriculados na rede escolar municipal do Rio de Janeiro. O bjetiva-se, a partir da análise destas representações, conceber caminhos para a avaliação da implantação do Programa de Saúde do Adolescente (PROSAD) no município, tendo em vista serem estes adolescentes usuários em potencial do referido programa.

As representações sociais, segundo Jovchel ovitch $^{5}$, são processos de mediação social, que têm a ver com comunicação ea vida, constituindo-seem estratégias que os sujeitos usam para enfrentar a diversidade e mobilidade de um mundo que, embora pertença a todos, transcende a cada um individualmente. Constituem-se em um processo dinâmico, ao mesmo tempo construídas e adquiridas, uma passarela entre os mundos individual e social ${ }^{6}$.

Embora não seja um conceito oriundo da psicologia social, é nesta que se dá sua teorização; o objeto apreciado migra do campo da sociologia para a interseção indivíduo e sociedade, torna-se segundo seu autor uma psicossociologia do conhecimento ${ }^{7}$.

M oscovici ${ }^{8}$ aponta dois eixos da construção das representações sociais, o social e o simbólico. Representar é um ato de pensamento que recoloca algo ausente ou distante, é re-apresentar, tornar presente ao espírito, à consciência. A representação exprime uma relação com o objeto, a repre- sentação é sempre de algo ou de alguma coisa, recolocando-a dentro do universo de apropriação do sujeito, no que ele conhece, implica um papel ativo do sujeito, sua forma de pensar e interpretar a realidade. É tornar o não-familiar familiar, aproximá-lo do sujeito e de sua realidade.

É a partir das representações sociais que se apreende os fatos da vida cotidiana, o conhecimento do senso comum, constituído a partir de nossas experiências e saberes. É um conhecimento socialmente elaborado e partilhado e é a partir dele que atuamos ${ }^{9}$. Através dos processos de objetivação e ancoragem, as representações sociais estabelecem suas mediações. A objetivação é uma operação imaginante e estruturante, que fornece uma estrutura material às idéias, condensando significados diversos. Esta estrutura imaginanteéo núcleo duro das representações sociai $s^{5}$. A ancoragem possibilita que a representação se articulecom sua origem social. Segundo J ovchelovitc ${ }^{5}$, as representações sociais emergem desse modo como processo que ao mesmo tempo desafia e reproduz, repete e supera, queéformado, mas quetambém forma a vida social deuma comunidade.

Abric $^{10}$ assinala que representação social é 0 produto e o processo de uma atividade mental pela qual um indivíduo ou um grupo reconstitui o real com que se confronta e lhe atribui uma significação espećfica. Diantedeste conceito, enfatiza que o comportamento dos sujeitos depende menos das características objetivas de dada situação do que das representações sociais que se constituem no seu fator determinante.

Abric ${ }^{11}$ propôs a existência de uma organização interna dos elementos da representação social em torno de um núcleo central, constituindo-se este, por sua vez, de elementos que dão à representação o seu significado. Em torno desse núcleo, organizam-seelementos periféricos - sistema periférico - , complemento indispensável que promove a interface en tre a real idade concreta e o sistema central, atualizando-o e contextualizando-0 constantemente, daí resultando sua mobilidade e flexibilidade, permitindo a expressão individualizada e tornando possível que a representação social se ancore na realidade do momento.

Abric ${ }^{12}$ sintetizou as características e funções dos sistemas da forma seguinte: o sistema central é ligado à memória coletiva e à história do grupo, é consensual, define a homogeneidade do grupo, é estável, coerente, rígido, resistenteà mudança, pouco sensível ao contexto imediato, gera a significação da representação social e determina sua organização. 0 sistema periférico permite a integração das experiências e histórias individuais, suporta a 
heterogeneidade e as contradições do grupo, é flexível, evolutivo, sensível ao contexto imediato, permite a adaptação à realidade concreta, a diferenciação do conteúdo, protege o sistema central.

Assim, a identificação dos possíveis el ementos dos sistemas central e periférico das representações sociais de saúde elaboradas pelos adolescentes poderá propiciar a aproximação com a forma como esta se adapta ao contexto imediato desses jovens, usuários do PROSAD do Rio de Janeiro. Tal fato poderá trazer subsídios à avaliação da implantação e planejamento de ações futuras do referido programa.

\section{Procedimentos metodológicos}

A redemunicipal de saúde do Rio de Janeiro conta com 97 unidades básicas (UBS), distribuídas em dez áreas programáticas (AP) ${ }^{13}$. Em cada $A P$, foi selecionada uma U BS em que o PROSAD já estava em processo de implantação e, tendo por base esta unidade, foram selecionadas duas escolas públicas, uma considerada "parceira" e outra "não parceira" daUBS. Esta parceria foi definida pela existência de algum tipo de trabalho conjunto entre a escola e a UBS. Assim, a pesquisa foi desenvolvida em vinte escolas, totalizando 1843 sujeitos de 14 a 18 anos.

Optou-se por trabalhar com a totalidade dos alunos de cada turma, visando minimizar a interferência na rotina escolar, contribuindo para a maior motivação dos sujeitos. Ao chegar às escolas, os pesquisadores esclareciam às turmas de alunos e aos profissionais presentes os objetivos da pesquisa, o caráter facultativo da participação, colocando-se disponíveis para esclarecer possíveis dúvidas. Como o tema abordado estava muito próximo ao universo dos alunos, estes se mostraram bastante colaborativos.

0 instrumento decoleta de dados continha um teste de evocação livre de palavras (TEP) ${ }^{12,14,15} \mathrm{e}$ perguntas abertas e fechadas com o objetivo de identificar o perfil sociodemográfico dos adolescentes e suas formas de interação com o tema e o serviço de saúde, objetivando contextualizar a análise das representações sociais. Este instrumento foi auto-preenchido, sendo que o TEP era efetuado com um breve treinamento com outros termos indutores, diferentes daquele a ser pesquisado $0^{16}$. Foi utilizado como termo indutor saúde, ou seja, era solicitado aos alunos que anotassem as quatro primeiras palavras que lhe vinham à cabeça ao ouvir a palavra saúde.

A análise dos resultados do TEP foi efetuada por meio da categorização das palavras evocadas com o auxílio do software EVOC, que possibilitou a classificação segundo as freqüências e ordem média de evocação. 0 perfil sociodemográfico dos sujeitos foi obtido a partir da análise das perguntas fechadas com o auxílio do software Epi Info 6.4c. Os resultados parciais foram sendo discutidos com as unidades envolvidas, fato que contribuiu, de forma importante, para a interpretação dos resultados obtidos.

Esta pesquisa foi analisada e aprovada pelo ComitêdeÉtica em Pesquisa do Núcleo de Estudos de Saúde Coletiva da UFRJ. Foram observadas as exigências vigentes sobre pesquisas envolvendo se res humanos, atentando-se para os cuidados me todológicos relativos aos princípios éticos, incluindo-se a relevância social, a viabilidade, a preservação da confidencialidade dos dados e a beneficência emal eficência do processo de investigação ${ }^{17}$.

Cabe destacar, ainda, que este trabal ho se insere dentro de um projeto maior desenvolvido pela Gerência do Programa de Saúde do Adolescente da Secretaria Municipal de Saúde do Rio de Janeiro, o Projeto de Indicadores de Saúde e D esenvolvimento de Adolescentes e Jovens, uma parceria entre a Organização Mundial de Saúde e o UNICEF, que o envolveu sete países ${ }^{18}$.

\section{Resultados ediscussão}

Optou-se por analisar os resultados a partir da comparação dos extremos de idades envolvidas, ou seja, trabalhou-se com o grupo etário de 11/12 anos e 17 /18 anos. Desta forma, buscou-se, dentro da imensa gama de diferenças que podem existir na faixa de idade que envolve a adolescência, observar melhor possíveis pontos em comum e diversos entrea faixa etária mais próxima ao início da adolescência e outra a seu final. Os dados foram analisados e comparados em relação a estes dois grupos.

Os grupos estudados eram constituídos, em sua maioria, por meninas (55\%), ainda no ensino fundamental $(62 \%)$, constatando-se um número expressivo cursando a quarta série ou em turma de aceleração $(5,6 \%)$, mostrando a flagrante defasagem idade/série. Um pequeno contingente $(1,3 \%)$ informou ser casada/o ou ter companheira/o, fato que também está de acordo com o perfil dos adolescentes que freqüentam os serviços públicos de saúde nessa cidade. Cerca de $9 \%$ referiram exercer algum tipo de atividade de trabal ho, a maioria relacionada a serviços domésticos, na própria família ou em outra, ou de comércio. Este perfil dos participantes desteestudo corresponde àquele dos 
adolescentes que buscam as unidades de saúde municipais referidos por Ruzany3.

O TEP foi respondido por 1.828 dos 1.843 sujeitos de 12 a 18 anos, totalizando 5.941 evocações. Destas, as dez que obtiveram maior freqüência, correspondendo a $67,4 \%$ do total (4.005 evocações) foram: importante (595), alimentação (456), médico (454), vida (446), doença (394), serviço de saúde deficiente (384), remédio (336), higiene (270) e cuidado (268).

Foi possível, a partir da análise das categorias evocadas e da sua ordem de evocação, construir um quadro que incluísse estas variáveis a fim de permitir melhor visibilidade destes resultados. Foram verificadas também as freqüências das evocações em cada uma das quatro posições, ou seja, realizado o somatório das freqüências em que a palavra foi evocada em cada posição.

A seguir, verificou-se, além da freqüência, a ordem média de evocação de cada uma destas categorias. A ordem média de evocação é obtida ponderando-se com peso 1 a evocação realizada em primeiro lugar, com peso 2 aquela real izada em segundo lugar e assim sucessivamente, com tantos índices de ponderação quanto for o número de associações solicitadas, no caso quatro. 0 somatório destes resultados, dividido pelo somatório das freqüências da categoria citada nas diversas posições, apontará a ordem de evocação da palavra ${ }^{15,19}$. A partir da média aritmética da ordem de evocação de cada palavra, chega-seà ordem média de evocação. Com a interseção destes dois dados, freqüência e ordem média de evocação, foi possível construir um diagrama em que os elementos são distribuídos em quatro quadrantes. Sendo o eixo vertical referenteà ordem média de evocação, desta forma elementos com ordem média de evocação menor ficarão nos quadrantes à esquerda e elementos com ordem média de evocação maior ficarão à direita. 0 eixo horizontal refere-se à freqüência de evocação, estando nos quadrantes superiores aqueles com fre qüências de evocação mais el evadas.

A fim deconstruir-se o diagrama mencionado, foi calculada a freqüência média de evocação e a média das ordens médias de evocação, os valores obtidosforam respectivamente 68 e 2,5 para o grupo etário de $12 / 13$ anos ( $\mathrm{N}=541$ ) e 54 e 2,5 para o grupo de $17 / 18$ anos ( $N=367$ ). Assim estes valores correspondem aos eixos vertical e horizontal. 0 diagrama construído, a partir destes valores, apre senta em seu quadrante superior esquerdo os ele mentos mais freqüentemente evocados (freqüência maior ou igual a 68 ou 54) e com ordem média de evocação menor, ou seja, mais prontamente evocados (ordem média de evocação menor que
2,5); estes elementos provavelmente participam do núcleo central da representação social. No quadrante inferior direito situam-se, opostamente, aqueles elementos evocados com menor freqüência (menor que 68 e 54) e mais tardiamente (ordem média deevocação maior ou igual a 2,5), provavelmenteintegrantes do núcleo periférico. Os elementos situados nos outros quadrantes exigem uma interpretação menos direta; considerando a relação de proximidade que estabelecem com 0 núcleo central, são relacionados a certa instabilidadequeéprópria da representação ${ }^{15}$. Foram construídos dois diagramas conforme os grupos etários de 12/13 anos e 17/18 anos.

O bservam-se elementos comuns que integram o núcleo central (estão no quadrante superior esquerdo dos diagramas): alimentação, hospital, importante e médico. No grupo etário de 17/18 anos, aparece também como elemento do núcleo central sistema de saúde deficiente. E no de 12/13 anos, doença, felicidade e vida.

São elementos comuns aos dois grupos que possivelmentecompõem o núcleo periférico (situam-se no quadrante inferior direito do diagrama): corpo e sexo. Sendo que elementos relacionados à prevenção, tais como prevenção e educação e camisinha e preocupação também aparecem, os primeiros no grupo de $17 / 18$ anos e os seguintes no grupo de 12/13 anos.

Ao encontrarem-se como elementos do núcleo central importante, alimentação emédico, é possível perceber o destaque que o tema saúde tem nos dias atuais para o adolescente, representado nos elementos: importante, felicidade e vida, reforçado por estes doisúltimos elementosno grupo etário de 12/13 anos. 0 adolescente está constantemente submetido a mensagens sobre 0 assunto e foco de uma série de ações, seja no âmbito da família, escola, serviço de saúde ou trabalho. Além do que, considerando-se o núcleo central como aquele mais arraigado à memória coletiva e à história do grupo, compreende-se a ligação de importante com saúde.

Já o elemento alimentação demonstra a preocupação positiva do adolescente em relação a sua saúde, algo intrinsecamentemais ligado à vida eda qual ele pode cuidar, ao cuidar de seu corpo através da alimentação. Tal fato também traz a ligação histórica desse elemento através das mensagens de quem cuida do adolescente ( pais, avós, etc.) quando se dá destaque à relevância da alimentação adequada para a manutenção ou obten ção de uma boa saúde. H ospital traz a ligação imediata do tema saúde com a doença, remontando à própria concepção inicial na construção da saúde, a partir da qual esta seria a ausência de doenças. A importân- 
Quadro 1. Distribuição dos elementos segundo freqüência de evocação e ordem média de evocação realizadas por adolescentes de 12/13 anos.

\begin{tabular}{|c|c|c|c|c|c|c|}
\hline fme & Elementos & $f$ & Ome $<2,5$ & Elementos & $f$ & Ome $\geq 2,5$ \\
\hline$\geq 68$ & $\begin{array}{l}\text { Vida } \\
\text { Alimentação } \\
\text { M édico } \\
\text { D oença } \\
\text { H ospital } \\
\text { Importante } \\
\text { Felicidade }\end{array}$ & $\begin{array}{r}165 \\
149 \\
147 \\
140 \\
119 \\
94 \\
78\end{array}$ & $\begin{array}{l}2.042 \\
2.208 \\
2.463 \\
2.171 \\
2.227 \\
2.213 \\
2.359\end{array}$ & $\begin{array}{l}\text { Remédio } \\
\text { Higiene } \\
\text { Cuidado }\end{array}$ & $\begin{array}{r}122 \\
9 \\
69\end{array}$ & $\begin{array}{l}2.754 \\
2.517 \\
2.623\end{array}$ \\
\hline$<68$ & $\begin{array}{l}\text { Alegria } \\
\text { Bem-estar } \\
\text { Boa } \\
\text { Cura } \\
\text { Enfermeira } \\
\text { Família } \\
\text { Posto } \\
\text { Saudável } \\
\text { Vacina }\end{array}$ & $\begin{array}{l}29 \\
19 \\
24 \\
13 \\
21 \\
24 \\
25 \\
60 \\
40\end{array}$ & $\begin{array}{l}2.414 \\
2.211 \\
2.167 \\
2.462 \\
2.238 \\
2.458 \\
2.400 \\
2.125 \\
2.375\end{array}$ & $\begin{array}{l}\text { Ambulância } \\
\text { Amor } \\
\text { Atividades físicas } \\
\text { Camisinha } \\
\text { Carinho } \\
\text { Corpo } \\
\text { Lazer } \\
\text { M orte } \\
\text { Necessidade } \\
\text { Paz } \\
\text { Pessoa } \\
\text { Preocupação } \\
\text { Sexo } \\
\text { Saúde oral } \\
\text { Sistema Saúde deficiente }\end{array}$ & $\begin{array}{l}12 \\
52 \\
31 \\
15 \\
16 \\
16 \\
18 \\
39 \\
10 \\
35 \\
11 \\
10 \\
10 \\
11 \\
35\end{array}$ & $\begin{array}{l}3.583 \\
2.615 \\
2.774 \\
2.800 \\
2.813 \\
3.000 \\
2.833 \\
2.615 \\
2.700 \\
2.943 \\
2.818 \\
2.500 \\
2.600 \\
3.182 \\
2.629\end{array}$ \\
\hline
\end{tabular}

Quadro 2. Distribuição dos elementos segundo freqüência de evocação e ordem média de evocação realizadas por adolescentes de 17/18 anos.

\begin{tabular}{|l|l|r|l|l|r|c|}
\hline fme & \multicolumn{1}{|c|}{ Elementos } & $\mathrm{f}$ & Ome $<2,5$ & \multicolumn{1}{|c|}{ Elementos } & $\mathrm{f}$ & Ome $\geq 2,5$ \\
\hline \multirow{3}{*}{$\leq 54$} & Importante & 145 & 2.310 & Atividade física & 61 & 2.787 \\
& Sist. Saúde deficiente & 124 & 2.234 & Doença & 82 & 2.561 \\
& Alimentação & 94 & 2.160 & Remédio & 62 & 2.758 \\
& M édico & 93 & 2.473 & Vida & 91 & 2.626 \\
& Hospital & 83 & 2.157 & & & \\
\hline \multirow{2}{*}{$<54$} & Bem-estar & 41 & 2.122 & Corpo & 22 & 2.500 \\
& Boa & 12 & 2.000 & Educação & 10 & 2.600 \\
& Cuidado & 49 & 2.347 & Exame & 11 & 2.818 \\
& Família & 14 & 2.071 & Felicidade & 32 & 2.750 \\
& Higiene & 48 & 2.063 & Prevenção & 32 & 2.656 \\
& M orte & 18 & 2.444 & Saudável & 26 & 2.538 \\
& Necessidade & 17 & 2.355 & Sexo & 19 & 3.053 \\
& & & & & \\
\hline
\end{tabular}

cia do elemento médico, provavelmente representando os profissionais de saúde, já que classicamente os médicos ocupam um papel de destaque na visão da clientela do sistema de saúde, traz con- sigo a possibilidade de reflexão para os próprios profissionais do papel de destaque atribuído a eles, pelos próprios adolescentes, na construção da re lação adolescente-serviço público de saúde. 
Encontram-se como elementos de destaque, comuns aos dois grupos: corpo e sexo. Entendendo o núcleo periférico como aquelequepermitea integração das experiências ehistórias individuais eque permite a adaptação à realidade concreta, percebe se 0 adolescente relacionando a saúde com seu corpo em transição e o início de sua vida sexual. A atenção com as doenças sexualmente transmissíveis e a aids também parece estar presente em ambos os grupos. No primeiro (12/13 anos), nos elementos camisinha e preocupação e no grupo de 17/ 18 anos com os elementos educação e prevenção.

Destaca-seo grandenúmero de el ementos presentes como prováveis elementos do núcleo perifé rico do grupo etário de 12/13 anos ao compará-lo com 0 outro grupo. 0 elemento amor aparececom elevada freqüência, também presente 0 elemento carinho, apontando uma visão romântica deste grupo quanto à saúde, elementos que não aparecem no grupo de 17/18 anos.

Fazendo parte do núcleo periférico do grupo etário de 12/13 anos, encontram-se ainda os elementos atividades físicas e lazer, mostrando de forma bastante interessante como 0 adolescente reconhece, nos dias de hoje, a importância das ações de prevenção de doenças e promoção da saúde. Desta forma, destacam práticas do cotidiano que podem depender, apenas, da disposição e disciplina individuais, mas, também, podem ser tratadas como mercadorias de consumo menos acessíveis, a partir do culto às academias, veiculado pela mídia.

É interessante notar que o elemento sistema de saúde deficiente encontra-se no sistema periférico do grupo etário de 12/13 anos eno sistema central do grupo etário de 17/18 anos. Ou seja, para os mais velhos, o sistema de saúde deficiente é algo mais consensual, mais rígido, ligado à história das vivências deste grupo, enquanto para os mais novoséal go ainda flexível, em evolução, que permite contradições.

Considerando que Abric ${ }^{10}$ assinala que "a representação é um conjunto organizado de opiniões, de atitudes, de crenças e de informações referentes a um objeto ou a uma situação" e afirma a sua interdeterminação pelo sujeito, pelo sistema social e ideológico em que este vive, é interessante observar que a atitude positiva do adolescente em relação à saúde parece de alguma forma distante daquela que classicamente os serviços de saúde voltados para os adolescentes adotam quando insistem em vêlos, não como sujeito de riscos, mas muitas vezes como o próprio risco.

Corroborando esta análise, vale lembrar que Kuschnir ${ }^{20}$, ao estudar os documentos oficiais que falam de saúde do adolescente e risco, constatou que há: “[...] uma percepção de negatividade que partem para justificar controlá-los, arrogando-se a autoridade de indicar-Ihes o caminho a seguir, através, deum lado da administração/medi calização eficaz de seus corpos e, de outro da ilusão de serem capazes de ditar as regras de construção da ambiência social que os deve cercar. Controlar, portanto, os fatores de risco significa controlar o próprio adolescente, moldá- lo a uma pré-concepção[...]".

Para Winnicott ${ }^{21}$, uma parte importante da avaliação de saúde éque "um adolescente não deve ser curado como se fosse um doente".

A atitude positiva dos adolescentes em relação à saúde, a princípio não pensando em risco, aparece bem mais claramente nos el ementos do sistema periférico do grupo etário de 17/18 anos: corpo, educação, exame, felicidade, prevenção, saudável e sexo. Elementos que apontam para a integração com suas experiências individuais atuais, sensível ao contexto imediato que vivenciam (corpo, felicidade, saudável, sexo), de iniciação da vida sexual lançando mão de instrumentos de cuidados com sua saúde (educação, exame, prevenção). No sistema periférico do grupo etário de $12 / 13$ anos- como já mencionado - surgem elementos positivos de conotação mais romântica: amor, carinho, elementos correlatos ao outro grupo, que indica corpo, sexo, camisinha. E surgem alguns elementos que mostram sua apreensão em relação ao vivido ou ao que está por ser vivido: preocupação e morte. Talvez porque este grupo esteja pensando nas modificações da adolescência que se inicia, diferentemente do outro grupo que já é mais velho, já tendo vivenciado diversas experiências, que para o grupo de 12/13 anos ainda são pouco comuns e, portanto, trazem medo.

Flament ${ }^{22}$ assinala que o núcleo periférico "assegura o funcionamento quase instantâneo da representação como grade de decodificação deuma situação". Quando se encontram no sistema periférico atividades físicas, corpo, sexo, educação e prevenção, percebe-seque as informações recentemente veiculadas pel os serviços de saúde quanto à prevenção de DST e aids e aquilo que a mídia veicula como a valorização das atividades físicas influenciaram na organização do sistema periférico da representação social de saúde dos adolescentes.

Uma preocupação para $\mathrm{Abric}^{10}$ éa forma como estas representações são organizadas e quais os fatores que determinam esta organização e sua eventual transformação, posto que serão determinantes de comportamentos e práticas a serem adotadas. Cabe, então, destacar que, ao se associar representações e práticas em saúde, não se intenciona estabelecer a crença em uma relação linear en- 
tre representações sociais e práticas, mas considerar a função reguladora das representações sociais, que se apresentam como um saber prático que se estrutura como um guia de opiniões, atitudes e comportamentos ${ }^{16,23}$. Desta forma, depreende-se a importância de seu conhecimento quando da estruturação das estratégias do PROSAD, bem como da avaliação das mesmas.

\section{Considerações finais}

Inicialmente, é interessante notar o perfil do adolescente usuário dos serviços de saúde, perfil este que nem sempre está em consonância com o pensado pelos profissionais de saúde. A maioria ainda não tem um parceiro fixo e muitos já desenvolvem alguma atividade laborativa, ainda que no âmbito doméstico.

Os diferentes sentidos atribuídos pelos sujeitos ao objeto caracterizam diferentes subjetividades sociais marcadas pelo contexto histórico e cultural desses adolescentes e isso contribui para a construção de diferentes formas de relações sociais que se estabelecem na busca da aten ção integral à saúde do adolescente.

Encontrou-seem comum no núcleo central das representações sociais dos dois grupos comparados importante, mostrando a valorização do tema para esses adolescentes; médico, apontando o papel de destaque que eles conferem a esses profissionais em relação à saúde e alimentação, destacando de forma positiva o olhar que têm sobre sua saúde, relacionando-a a al go que está sob seu controle, da qual ele pode cuidar tratando de seu corpo com uma "alimentação adequada".

Observou-setambém como el ementos comuns dos sistemas periféricos das representações sociais dos adolescentes corpo e sexo, destacando a importância destes dois elementos na elaboração e de- senvolvimento de programas e ações voltadas para a saúde do adolescente.

Nos elementos prevenção, educação, exame e preocupação, percebe-se também nos dois grupos a atenção com a prevenção de doenças, apontando também possibilidades de caminhos a serem percorridos pelo PROSAD.

Numa observação geral da leitura das evocações realizadas pelos adolescentes, percebe-se um enfoque mais positivo em relação à saúde. Embora elementos como hospital, doença, ambulância apareçam, em momento algum o risco, tão falado pelos profissionais desaúde, foi explicitado. Contudo, outros elementos com conotação positiva foram observados: paz, amor, saudável, carinho, alegria, vida, atividades físicas, lazer, al imentação, mostrando possíveis linhas de diálogo a serem exploradas entreo PROSAD eos adolescentes, talvez mudando um pouco o enfoque de risco e de vulnerabilidade que muitas vezes afeta os adolescentes, tendo visto que não é desta forma que percebem a saúde.

Percebe-se o campo das representações sociais um campo fértil, ainda a ser mais explorado para trabalhos na área de saúde do adolescente, pois poucos são os trabalhos voltados ao estudo das representações sociais de adolescentes. Estes estudos podem fornecer informações aos serviços de saúde, contribuindo para a definição de estratégias efetivas dirigidas à captação efixação destes adolescentes às ações do programa, integrando-os na construção e avaliação do PROSAD.

Cabe destacar que, ao se associar representações e práticas em saúde, não se intenciona levar a crer na existência deuma relação linear entre representações sociais e práticas, mas considerar quesendo as representações um saber prático, este seestrutura como um guia de comportamentos e atitudes. D esta forma, depreende sea importância de seu conhecimento quando da estruturação das estratégias do PROSAD, bem como da avaliação das mesmas. 


\section{Colaboradores}

LM F Cromack, I Bursztyn e LFR Tura participaram igualmente de todas as etapas da elaboração do artigo.

\section{Referências}

1. Ayres JRCM, França Júnior I, Calazans GJ, Saletti Filho HC. Vulnerabilidade e prevenção em tempos de AIDS. In: Barbosa RM, Parker RP, organizadores. Sexualidades pelo avesso: direitos, identidades e poder. Rio de Janeiro: Editora 34, 1999. p. 49-72.

2. Branco VMC. Os sentidos da saúde dos adolescentes para os profissionais. [dissertação]. Rio de Janeiro (RJ): Universidade Federal do Rio de Janeiro; 2002.

3. Ruzany M H. M apa da situação de saúde do adolescente no município do Rio de Janeiro [tese]. Rio de Janeiro (RJ): Fundação O swaldo Cruz; 2000.

4. Ayres JRC, Calazans GJ, França Júnior I. Vulnerabilidade do adolescente ao HIV/AIDS. In: Vieira EM, Fernandes M EL, Bailey P, M ackay A, organizadores. Seminário gravidez na adolescência. Brasília: Cultura Editores Associados; 1998. p. 97-109.

5. Jovchelovitch S. Vivendo a vida com os outros: intersubjetividade, espaço público e representações sociais. In: Guareschi P, Jovchelovitch S, organizadores. Textos em representações sociais. 6a ed. Petrópolis: Vozes; 2000. p. 63-88.

6. Moscovici S. Das representações coletivas às representações sociais: elementos para uma história. In: Jodelet $D$, organizador. As representações sociais. Rio de Janeiro: Eduerj; 2001. p. 45-66.

7. Farr RM. Representações sociais: a teoria e sua história. In: Guareschi P, Jovchelovitch S, organizadores. Textos em representações sociais. 6a ed. Petrópolis: Vozes; 2000. p. 31-57.

8. Moscovici S. Representações sociais: investigações em psicologia social. Petrópolis: Vozes; 2003.

9. Jodelet $D$. Representações sociais: um domínio em expansão. In: Jodelet $D$, organizador. As representações sociais. Rio de Janeiro: Eduerj; 2001. p. 17-44.

10. Abric JC. O estudo experimental das representações sociais. In: Jodelet $D$, organizador. As representações sociais. Rio de Janeiro: Eduerj; 2001. p. 155-71

11. Abric JC. L'organization interne des représentations sociales: système central et systemème périphérique. In: Guimelli C, editeur. Structures et transformations des représentations sociales. Lausanne: Delachaux et Niestlé; 1994. p.73-83.

12. Abric JC. L'analyse structurale des représentatrions socials. In: Moscovici S, Buschini F, editeurs. Les méthods des sciences humaines. Paris: PUF; 2003. p. 375-392.
13. Rio de Janeiro. Prefeitura da Cidade. Secretaria M unicipal de Saúde. Guia de saúde da cidade do Rio de Janeiro. Rio de Janeiro: Imprensa da Cidade; 1999.

14. Camargo BV. Sexualidade e representações sociais da Aids. Revista de Ciências Humanas 2000; 3(Supl.): $97-$ 110.

15. Sá CP. Núcleo central das representações sociais. Petrópolis: Vozes; 1996.

16. Tura LFR. Aids e estudantes: a estrutura das representações sociais. In: Jodelet D, M adeira M C, organizadores. Aids e representações sociais: à busca de sentidos. Natal: EDUFRN; 1998. p.121-154.

17. Brasil. Conselho Nacional de Saúde. Resolução no 196 de 10 de outubro de 1996. Aprova diretrizes e normas regulamentadoras de pesquisas envolvendo seres humanos. Diário Oficial da U nião 1996; 16 out.

18. World Health Organization/Unfppa/Unicef. The second decade: improving adolescent health and development. Geneve: WH O; 1998.

19. Vergès $P$. Approche du noyau central: propriété quantitatives et structurales. In: Guimelli C, editeur. Structures et transformations des représentations sociales. Lausanne: Delachaux et Niestlé; 1994. p. 23353.

20. Kuschnir MCC. Adolescentes: sujeitos do risco, indivíduos com medo. As concepções de saúde/doença, de risco e de ser adolescente [dissertação]. Rio de Janeiro (RJ): Fundação Oswaldo Cruz; 1996.

21. Winnicott DW. Tudo começa em casa. São Paulo: M artins Fontes; 1999.

22. Flament $C$. Estrutura e dinâmica das representações sociais. In: Jodelet $D$, organizador. As representações sociais. Rio de Janeiro: Eduerj; 2001. p. 173- 186.

23. Moreira ASP, Soares CCC, Jesuino JC, Cardoso M BC, Gaspar MFM. Representações sociais do tabaco pelo olhar de estudantes de enfermagem. In: Moreira ASP, Jesuino JC, organizadores. Representações sociais: teoria e prática. 2a ed. João Pessoa: EdUFPB; 2003. p. 481-503.

Artigo apresentado em 11/12/2006

Aprovado em 26/01/2007

Versão final apresentada em 05/04/2007 